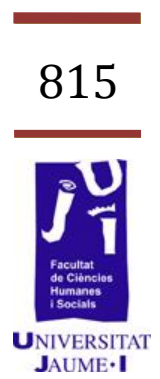

\title{
L'orientació dels estudiants amb discapacitat de la Universitat Jaume I
}

Irene Garcia Molina imolina@uji.es 


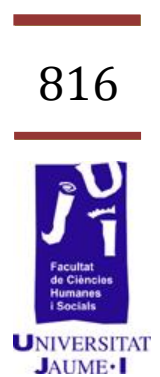

Agraïments $a$ : Lola Arias Albareda Marcos Llorens Ribes Aida Sanahuja Ribés 
I. Resum

L'objectiu d'aquesta investigació és conèixer la percepció que tenen sobre l'orientació els alumnes amb discapacitat de la Universitat Jaume I (UJI). Aquest treball, parteix d'un treball previ realitzat en el 2011 per varies estudiants entre qui es troba l'autora d'aquest estudi actual). En el primer, es va realitzar un primer anàlisi, enfocant les dades recollides en quatre tipus de població: alumnes amb discapacitat, professors, companys d'alumnes amb discapacitat i personal d'administració i serveis.

Es tracta d'un disseny de tipus descriptiu, que utilitza el mètode d'enquesta i com a instrument el qüestionari, realitzat per les integrants del primer estudi. A més, també s'hi afegeixen dades per mitjà de l'entrevista a un subjecte amb discapacitat, que dóna una visió més concreta sobre el tema a analitzar.

Els resultats, semblen indicar que la majoria dels estudiants amb discapacitat han rebut Orientació Escolar i opinen que aquesta els ha servit per prendre decisions futures; destaca l'orientació Informativa i d'Assessorament, i aquella rebuda al Batxillerat; a més, destaca que la meitat d'aquests ha buscat orientació fora del Centre Escolar. Pel que fa a les respostes qualitatives, denoten aquest últim ítem i resolen dubtes entorn a les respostes dicotòmiques del qüestionari.

Paraules clau: orientació, discapacitat, assessorament, Centre de Recursos Educatius (CRE), Unitat de Suport Educatiu (USE).

\section{Introducció}

L'Orientació Educativa es defineix com un procés d'ajuda continu i sistemàtic dirigit a totes les persones, en tots els seus aspectes, amb la finalitat de potenciar el desenvolupament humà al llarg de tota la vida (Bisquerra-Alzina, 1996).

És per això, que l'estudi que a continuació es presenta pregunta per tota la vida acadèmica d'aquest estudiantat, no es centra només en la Universitat (tot i donar-li més pes, ja que tota la mostra la composen estudiants universitaris amb algun tipus de discapacitat).

Orientació i inclusió, són termes relacionats. És necessària una orientació adequada, d'assessorament, informativa, vocacional..., perquè alumnes (sobretot amb discapacitat) puguin accedir al Sistema Educatiu, i continuar en ell fins la Universitat. La diversitat ha d'ésser present en l'educació, així com ho és a la vida.

La diversitat entesa per Bayot, Rincón y Hernández (2002), remarca que els diferents àmbits educatius atendran a la diversitat, tan sols si parteixen i aprofiten les diferències per al creixement de l'individu i el 
col-lectiu en general. Així doncs, s'ha d'aprofitar aquesta riquesa que ens dóna la diversitat, tant des de l'àmbit educatiu com des de la pròpia societat.

Però, què és necessari perquè existeixca aquesta inclusió? En la investigació de Bilbao (2010) se'ns citen diversos factors influents: els recursos naturals que formen part de la Universitat (personals, materials, contextuals i organitzatiu), les actituds d'acceptació i respecte, la participació dels propis estudiants amb discapacitat en les decisions que afecten a les seves vides: I'autodeterminació, i la consideració de l'atenció a la diversitat com a estàndard de qualitat educativa.

Aquesta investigació, que es basa en la importància que dona el professorat als diferents recursos citats, conclou que hi té major significació les infraestructures accessibles, els centres de recursos i el professorat de recolzament especialitzat $i$ les unitats de recolzament $i$ assessorament, perquè aquests estudiants tinguin les mateixes oportunitats en la seva vida acadèmica.

Cal remarcar, que aquests factors, no només s'han quedat en la teoria sinó que s'han dut a la Pràctica pel Servei de Suport de la Universitat de València (Alcantud, Ávila i Asensi, 2000). Aquest és considerat com a pioner i referent a nivell nacional i també a nivell europeu. L'objectiu d'aquesta organització de drets específics és restablir o almenys aproparse a l'equiparació de tots, superant aquesta desigualtat, amb el tracte desigual (discriminació positiva) als més desfavorits (Rivas, 1997).

Com s'ha anat redactant, el recolzament i l'assessorament són recursos ben importants per a l'alumnat amb discapacitat; és per això que aquest estudi es centra més en aquesta part. A més, aquest, parteix d'un primer treball pilot "La Orientación en la Educación Superior. Universitat Jaume I", realitzat per les alumnes de Psicopedagogia: Lola Arias Albareda, Irene Garcia Molina i Aida Sanahuja Ribés; que es basava en la percepció de l'orientació per part de tota la comunitat universitària (professorat, alumnat, personal d'administració i servei i alumnat amb discapacitat).

En aquest primer estudi, moltes preguntes suposaven interrogants, com per exemple, un $50 \%$ de respostes de l'alumnat amb discapacitat que elegeixen la recerca d'ajuda i orientació fora del Centre Escolar; és per això que aquest primer estudi, s'ha centrat només en l'apartat d'alumnat amb discapacitat, per intentar respondre a aquests per quès. Si més no, si les conclusions primeres són més generals, és en l'entrevista a un alumne amb discapacitat, on es relaciona d'una forma més clara l'orientació i la percepció de la inclusió que hi té. Així doncs, s'hi comparen les respostes de 20 alumnes amb discapacitat amb les respostes qualitatives de l'entrevista; per poder contrastar les dades sobre l'orientació rebuda durant la vida acadèmica d'aquest collectiu. 
III. Objetius

El següent treball es planteja aquests objectius:

-Identificar el tipus d'orientació que han rebut 20 alumnes amb discapacitat de la Universitat Jaume I durant la seva vida acadèmica.

-Contrastar aquestes dades amb l'entrevista a un estudiant de la Universitat Jaume I amb discapacitat visual.

\section{Material i metodologia}

\section{Mostra}

La mostra, la formen 20 estudiants amb discapacitat de la UJI, d'edats compreses entre 19- 50 anys, dels quals el $45 \%$ ( 9 subjectes) són homes i 55\% (11 subjectes) són dones. Aquests, provenen de diferents titulacions, com ara: Psicopedagogia, Màster en màrqueting, Grau en Enginyeria Mecànica, Magisteri, Doctorat, Màster de Secundària, Grau en Enginyeria d'edificació, Psicologia, Administració i Direcció d’Empreses, Ciències empresarials, Doctorat en Màrqueting i Investigació de Mercats, i Enginyeria Informàtica.

Dels enquestats, trobem 15 subjectes amb algun tipus de discapacitat física i 5 amb algun tipus de discapacitat sensorial; d'aquests, són 2 els estudiants amb discapacitat auditiva i 3 amb visual. El subjecte que realitza l'entrevista és d'aquest últim grup.

\section{Instruments}

Per a recollir les dades sobre l'orientació, es va crear l'instrument: Un qüestionari de 6 ítems que fou redactat per les integrants del primer estudi del que parteix aquest treball. Les preguntes que en ell s'inclouen són les següents:

1. Carrera/Tipus de discapacitat

2. Durant la teva vida acadèmica, has rebut algun tipus d'orientació? Si / No

3. Per part de qui?

Orientador escolar Persona externa al centre o als meus estudis

4. Quin tipus d’orientació has rebut?

Acadèmica Professional Informativa Assessorament

5. En quina etapa educativa?

Primària Secundària Batxillerat FP Carrera Món laboral

6. T’ha sigut útil per prendre decisions futures?

$\mathrm{Si}$

No

Ja que accedir a la mostra, que en principi era de 60 subjectes, era complicat, s'han recollit les dades, mitjançant la pàgina web de: 
www.encuestafacil.com, una forma fàcil i ràpida per a que la mostra respongui al qüestionari.

\section{L'entrevista}

L'entrevista ha sigut elaborada a partir dels mateixos ítems que el qüestionari, per així, poder comparar d'una forma més fàcil les diferents respostes d'un instrument i de l'altre.

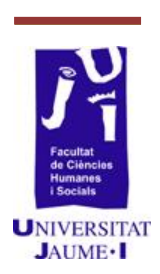

\section{Disseny}

Respecte al disseny metodològic que s'ha utilitzat en el treball de recerca es tracta d'un disseny de tipus descriptiu, que utilitza el mètode d'enquesta i com a instrument el qüestionari. En la segona part del treball, s'utilitza l'entrevista, per tal d'extreure informació més detallada.

Es tracta d'un disseny descriptiu, ja que els dissenys no-experimentals tal com han estat definits per Arnau (1995) són aquells en els quals ni s'aleatoritza ni es manipula, és a dir, respecten al màxim la situació natural de l'objecte d'estudi.

En el nostre estudi no es pretén manipular, sinó que es vol analitzar l'orientació que han rebut els alumnes amb discapacitat de la UJ, i respondre a unes qüestions més concretes mitjançant l'experiència d'un d'aquests alumnes.

El tipus de mostra és no-probabilístic, ja que només servirà per donar valoracions subjectives. Per a obtenir la mostra s'han seguit aquests passos:

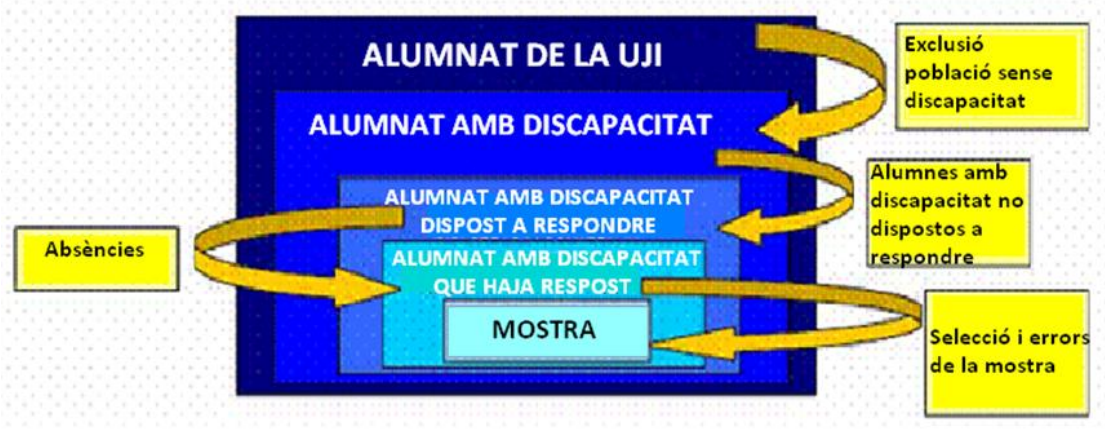

Figura 1. Mostra

\section{Resultats}

Primera part. Qüestionari administrat a 20 participants.

Els resultats del qüestionari s'hi observen mitjançant les gràfiques que es presenten a continuació. Més tard, es transcriu l'entrevista per comparar les diferents respostes.

Ítem 2: El 80\% dels enquestats afirma haver rebut algun tipus d'orientació al llarg de la seva vida acadèmica. 


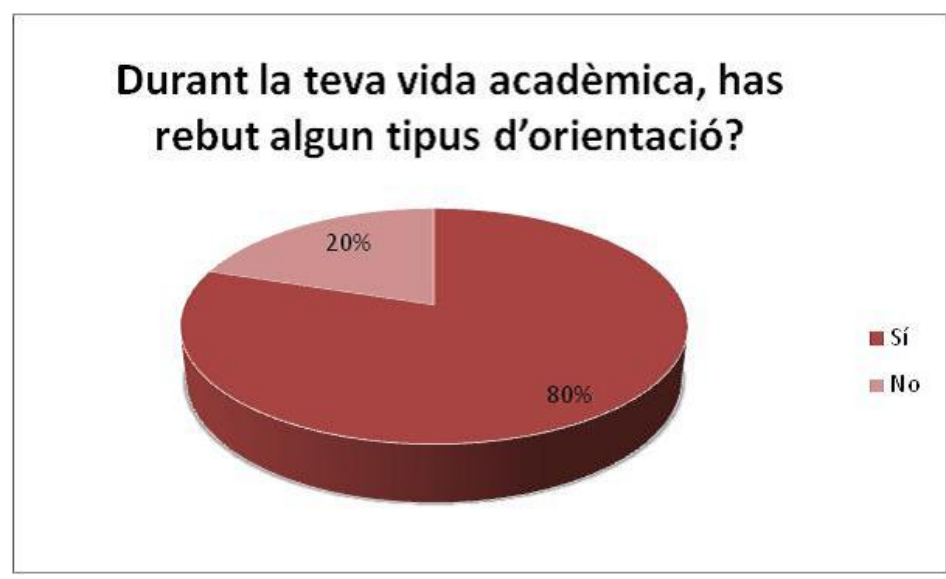

Figura 2. Orientació rebuda

Ítem 3: El 50\% dels enquestats afirma haver rebut aquesta orientació per part de l'orientador escolar, mentre que l'altre $50 \%$ afirma haver rebut l'orientació per part d'una persona externa al centre o als seus estudis. En aquesta pregunta es recuperen dades del primer estudi, amb percentatges de cada grup (estudiants, PAS, professorat i alumnat amb discapacitat).

\section{Estudiants}

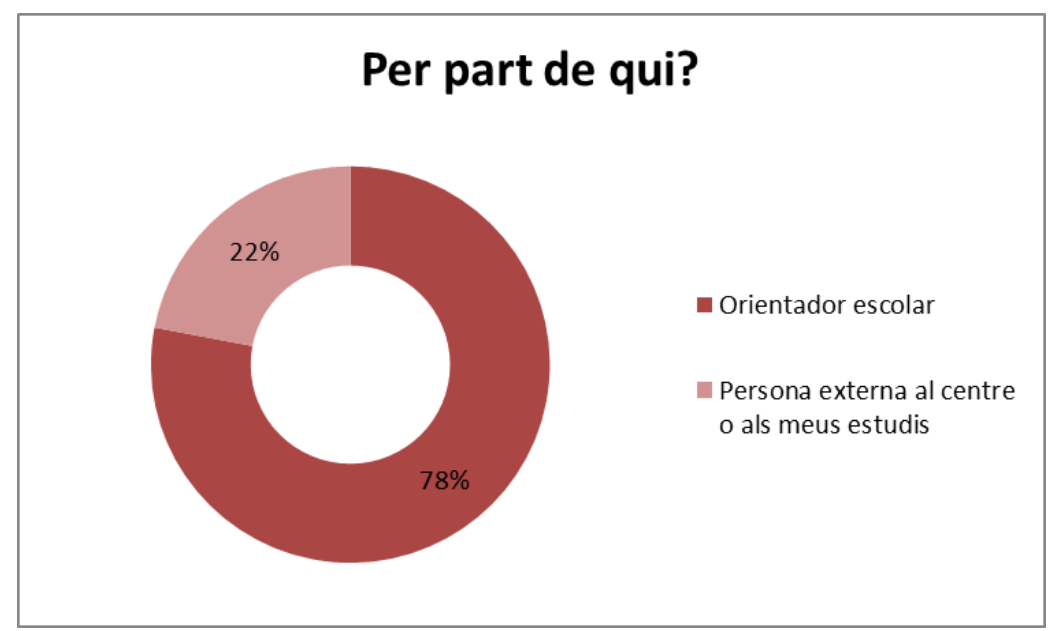

Figura 3. Estudiants. Per part de qui? 
Personal administratiu i de serveis

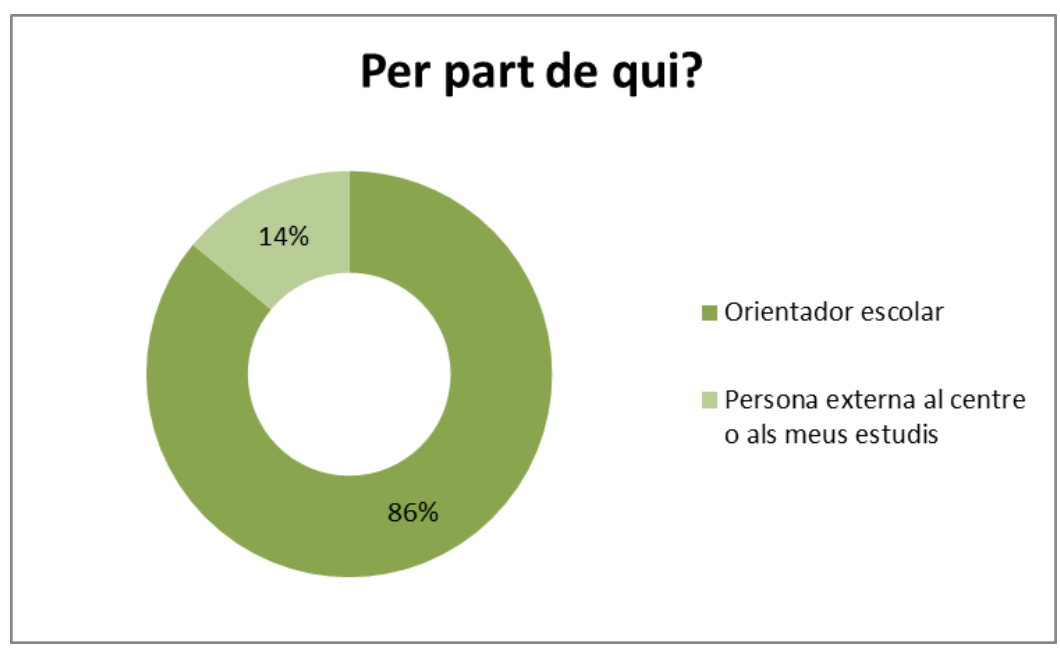

Figura 3. PAS. Per part de qui?

\section{Professorat}

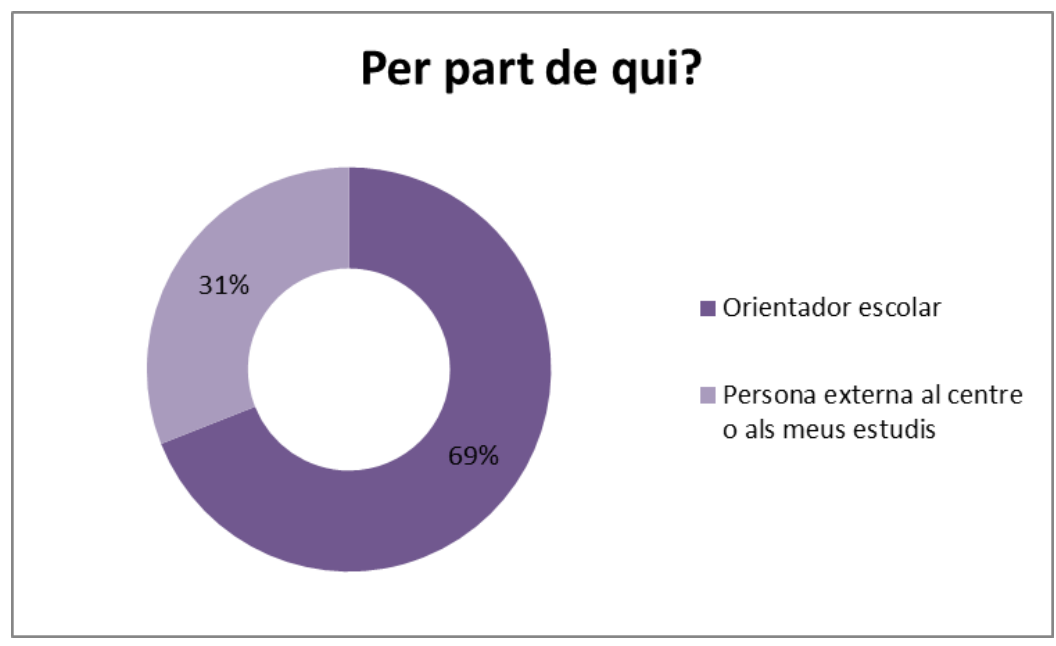

Figura 4. Professorat. Per part de qui? 
Estudiants amb discapacitat
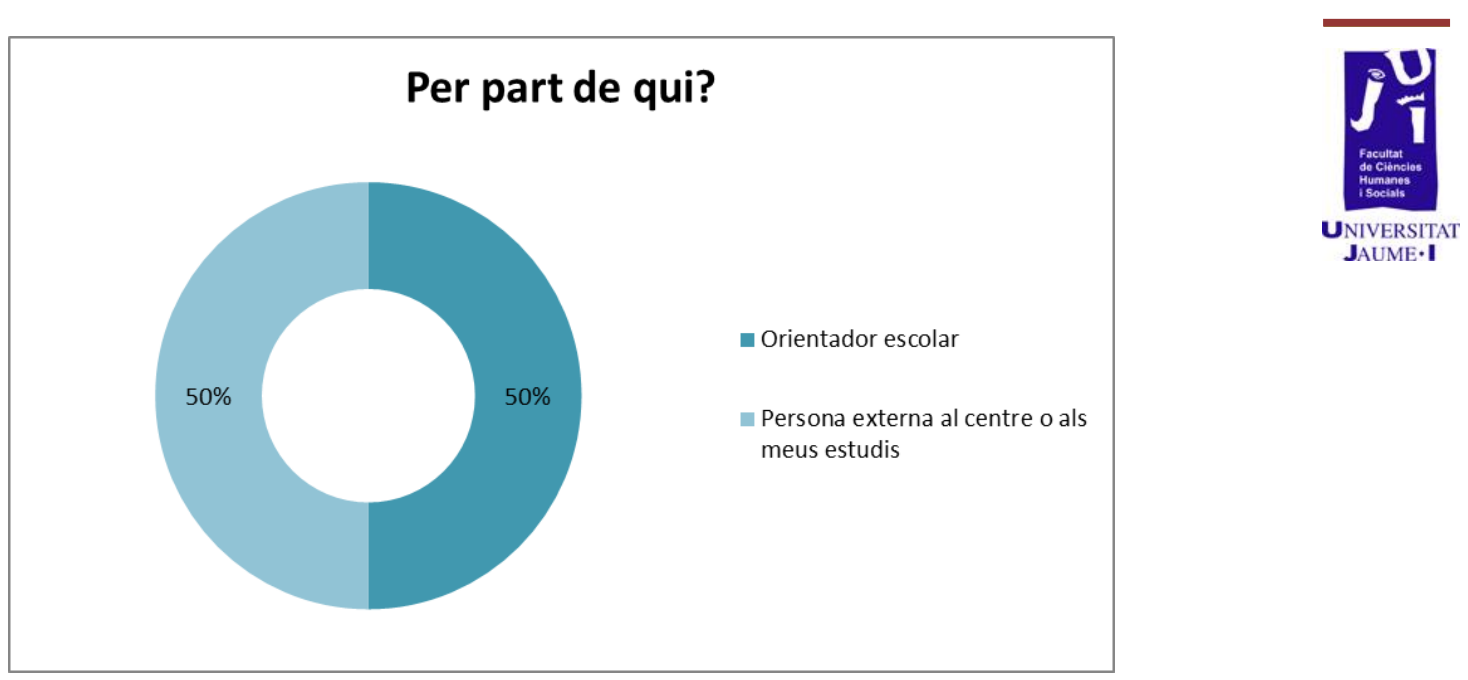

Figura 5: Estudiants amb discapacitat. Per part de qui?

Ítem 4: A la pregunta "Quin tipus d'orientació has rebut?", el 33\% dels enquestats ha respost orientació acadèmica, el 7\% professional, el 27\% informativa i el 33\% d'assessorament.

\section{Quin tipus d’orientació has rebut?}

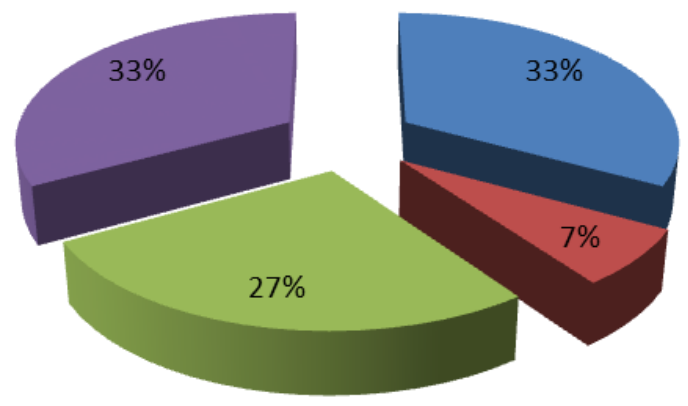

- Acadèmica

- Professional

- Informativa

Assessorament

Figura 6. Tipus d'orientació 
Ítems 5: A la pregunta en quina etapa educativa ha rebut l'orientació educativa, un $6 \%$ dels enquestats ha contestat que en educació primària, un $31 \%$ dels enquestats ha contestat en secundària, $38 \%$ ha contestat en batxillerat, un $19 \%$ en la carrera, un $6 \%$ al món laboral i ningú dels enquestats ha escollit l'opció de FP.

\section{En quina etapa educativa?}

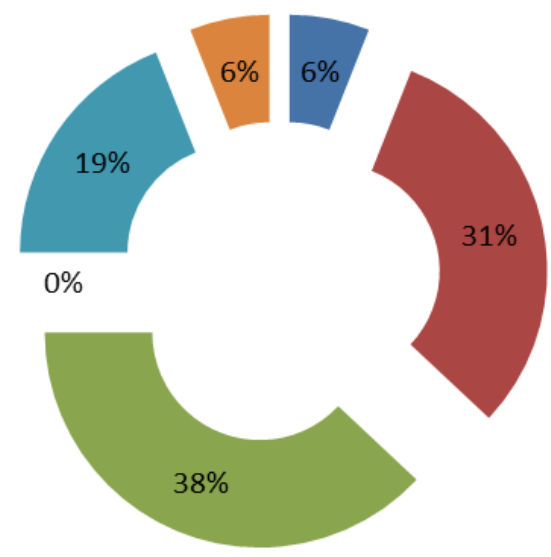

- Primària

- Secundària

- Batxillerat

$\square \mathrm{FP}$

Carrera

Món Laboral

Figura 7. Etapa educativa

Ítem 6: T'ha estat útil en la presa de les teves decisions futures?, el $75 \%$ dels enquestats ha respost que si, mentre que un $25 \%$ no li ha estat d'utilitat en la presa de les seves decisions futures.

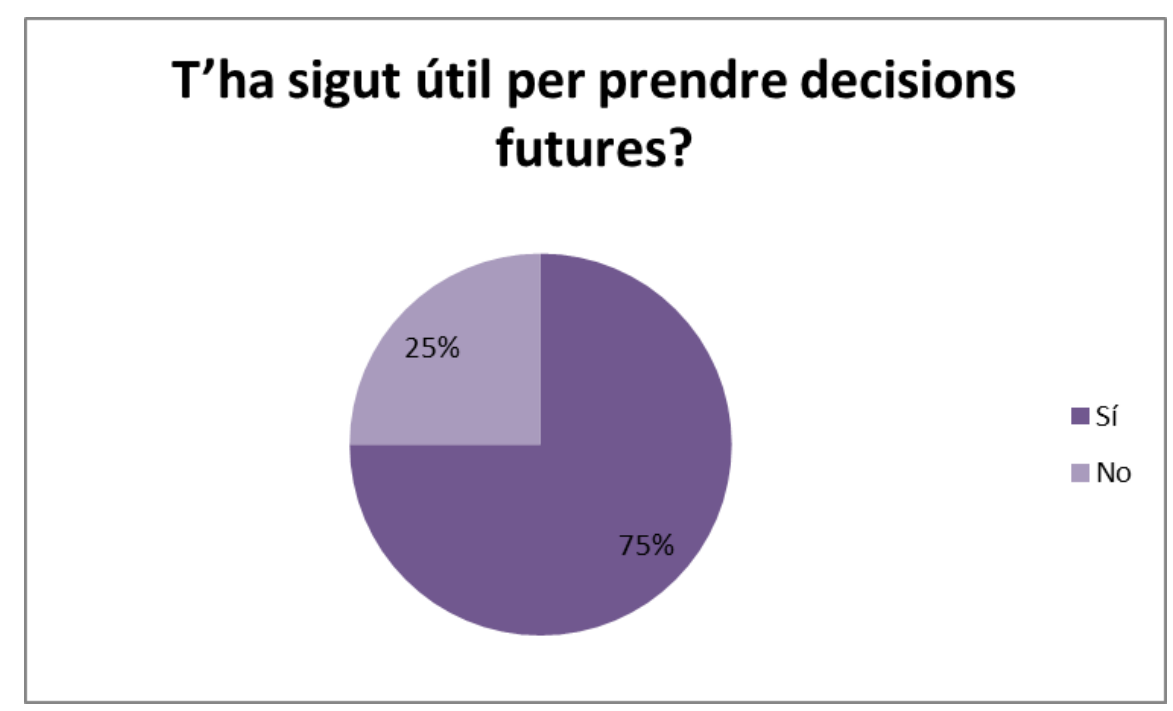

Figura 8. Utilitat de l’orientació 
Segona part. Entrevista qualitativa a un participant:

1. Carrera/Tipus de discapacitat: Psicologia/Visual

2. Durant la teva vida acadèmica has rebut algun tipus d'orientació?

Si. Pel que fa a Primària i Secundària, fou l'ONCE l'encarregada sempre de tot, ja que vaig cursar aquestes etapes en un Centre de Recursos Educatius (CRE). Potser on vaig notar que va fallar una mica l'orientació fou en Batxillerat, ja que jo tenia un bon nivell en Matemàtiques, però no m’orientaren bé, i vaig agafar el Batxillerat Científic; així que vaig repetir, i ja l'any següent em vaig canviar al Social.

3. Per part de qui?

Sobretot per part de la ONCE sempre he rebut orientació; també I'he rebuda de l'orientador de l'institut, però en aquest cas, va ser errada. La veritat, es que sempre que he tingut algun problema, he buscat ajuda fora, en l'ONCE.

4. Quin tipus d'orientació has rebut?

Acadèmica: pel que fa a la modalitat de batxillerat, informativa: per a la preparació per a selectivitat, les diferents sortides que tindria... I ja més, pel que fa orientació en recursos, en l'ajut del dia a dia, l'ONCE m'ha proporcionat programes informàtics, però també els amics han ajudat molt per a adaptar-me més tecnològicament a les diferents matèries.

5. En quina etapa educativa?

En batxillerat, al ser el canvi cap a la Universitat i l'elecció de modalitat, carrera...

6. T’ha sigut útil per al teu futur?

Si, sinó no hagués arribat fins aquí.

Pel que fa a la UJI, no he tingut mai cap problema, i la Unitat de Suport Educatiu (USE) crec que fa un paper molt important. Però la veritat, és que m'agradaria fer una cridada d'atenció. Crec que, una vegada s'acaba la universitat, et quedes una mica desproveït. Ara, sóc llicenciat, tinc la meva titulació, però sóc un més en aquesta gran selva.

El que pense és que, si hi ha beques per a estudiants, també deuria haverhi per a titulats amb discapacitat. Que es creïn places, que se'ns tingui en consideració una volta acabada la carrera, i se'ns doni una oportunitat, així com se'ns ha donat durant la vida universitària. 


\section{Discussió i conclusions}

L'orientació acadèmica que ha demostrat ser una eina valuosa per a l'èxit acadèmic dels estudiants universitaris amb algun tipus de discapacitat pareix ser, com demostren els resultats, una mesura que han rebut la majoria dels estudiants entrevistats $i$ açò ha sigut així durant la seva vida acadèmica (80\%). En la pregunta "Per part de qui?" s'han recuperat les respostes de la mostra del primer estudi, per comparar d'aquesta forma la diferència que existeix en els diferents grups (professorat, estudiants i PAS) amb els estudiants amb algun tipus de discapacitat. Així, trobem que pel que fa a dits estudiants, el $50 \%$ ha buscat orientació per part d'una persona externa al centre o als seus estudis, cosa que marca molt la diferència amb, per exemple els estudiants ( $78 \%$ han rebut orientació en el propi Centre Escolar). Pel que fa al tipus d'orientació trobem que el 33\% correspon a Orientació Informativa i d'Assessorament, sent aquestes les més elegides. Amb un $38 \%$, trobem que els estudiants amb discapacitat han rebut més orientació durant el Batxillerat (38\%); i la majoria d'aquests estudiants (75\%) opinen que aquesta orientació els ha servit per prendre decisions futures.

A més d'aquests resultats, també en l'article es recullen les respostes qualitatives de l'entrevista feta a l'alumne entrevistat individualment. En aquest cas, totes coincideixen amb la majoria de les respostes donades en el qüestionari per 20 estudiants.

Però així, com ens plantejàvem a la introducció, trobem que ens aporta informació nova a aquesta primera percepció. Com per exemple en la pregunta de "Per part de qui?" i durant les altres preguntes, on se'ns resol un dubte del primer estudi: El nostre subjecte, ens relata com sobretot ha rebut Orientació per part d'una associació externa al Centre Escolar: "Pel que fa a Primària i Secundària fou l'ONCE l'encarregada sempre de tot"; "Sobretot per part de la ONCE sempre he rebut orientació"; "La veritat, és que sempre que he tingut algun problema, he buscat ajuda fora, en l'ONCE"...

En aquest apartat però, s'ha de remarcar que la ONCE, és una Corporació molt forta, com el seu nom indica, és l'Organització Nacional de Cecs Espanyols, és a dir, que abasta tot el país; per tant té molts recursos i ajudes per donar assessorament a tots aquells membres de l’Organització.

A més, espontàniament, en una pregunta, ha sorgit un objectiu en el que no s'havia pensat: Donar-li veu a aquest col-lectiu i que puguin donar la seva opinió i expressar el seu content o descontent, d'aquesta pròpia Universitat. 
Les possibles línies a seguir d'aquest treball, es completarien amb més entrevistes amb estudiants de diferents tipus de discapacitats, l'ampliació de la mostra, enfocar l'orientació en la UJI... I també, partint d'aquesta última pregunta, es podria fer un estudi sobre els problemes que es tenen per a continuar en la UJI una volta acabats els estudis. A més, un estudi complementari d'aquest podria ser, conèixer la percepció dels estudiants discapacitats i antics alumnes de la UJI.

Amb tot, cal ressaltar la importància de una Orientació adequada per part de psicopedagogs i demés especialistes, perquè sobretot aquest col-lectiu pugui encaminar la seva vida cap allà on desitge, sense obstacles, barreres, o impediments.

\section{Bibliografia}

AlCANTUD, F. (1995a). "Estudiantes con discapacidades integrados en los estudios universitarios: notas para su orientación», en RIVAS, F. (ed.), Manual de asesoramiento y orientación vocacional. Ed. Síntesis. Madrid.

Alcantud Marín, F., Ávila Clemente, V. i Asensi Borrás, M.C. (2000). La integración de Estudiantes con Discapacidades en los Estudios Superiores. Valencia: Universita de Valencia Estudi General.

ARnAU, J. (1995). "Metodología de la investigación psicológica», EN Anguera, M.T., Arnau, J., Ato, M., Martínez, R., Pascual, J. y Vallejo, G. (ed.), Métodos de investigación en psicología (pp. 23-43). Síntesis: Madrid.

Bayot Mestre, A., del Rincón igea del, B. \& Hernández Pina, F (2002). "Orientación y atención a la diversidad: descripción de programas y acciones en algunos grupos emergentes», Revista Electrónica de Investigación y Evaluación Educativa, 8, 1.

BILBAO LEÓN, MC., (2010). "Percepción de los recursos que favorecen la integración de estudiantes con discapacidad en la Educación Superior según los docentes de la Universidad de Burgos», Educación y Diversidad, 4 (2), pp. 33-50.

Bisquerra AlzinA, R., (1996). Orígenes y desarrollo de la orientación psicopedagógica. Madrid: Narcea.

RIVAS, F. (1997): «Principio de igualdad de oportunidades y orientación universitaria en estudiantes con discapacidad", en ALCANTUD, F. (ed.), Universidad y diversidad (pp. 3-28). Universitat de Valencia. Valencia. 
